\title{
Micronutrient status of Palestinian school children following salt and flour fortification: a cross-sectional study
}

\author{
Salwa Massad ${ }^{1 *}$ D, Mehari Gebre-Medhin ${ }^{2}$, Omar Dary $^{3}$, Marwah Abdalla ${ }^{4}$, Steve Holleran ${ }^{5}$, Wahida Karmally ${ }^{6}$,
} Paula Bordelois ${ }^{7}$, Umaiyeh Khammash ${ }^{1}$ and Richard J. Deckelbaum ${ }^{5,8}$

\begin{abstract}
Background: In 1996 and in 2006, Palestine initiated salt iodization and multiple micronutrient fortification of wheat flour, respectively as a strategy to prevent deficiencies of these nutrients. In 2009, we assessed the impact of these interventions on the health and nutritional status of schoolchildren residing in the West Bank.

Methods: We surveyed a sample of 22 schools run by the UN Relief and Works Agency for Palestine Refugees in the Near East (UNRWA) and the Palestinian Government. We randomly selected students from the first (mean age 6.7 years [SD 0.5]), sixth (11.8 years [0.6]), and ninth grades (14.8 years [0.6]). Data were obtained from 1484 (99\%) of 1500 students planned for enrollment.

Results: Our results suggest that iodine intake appears adequate and there was essentially no iodine deficiency. As to the status of other micronutrients, the main nutritional micronutrient risks for schoolchildren in the West Bank continue to be low serum levels of iron, zinc, and vitamin B-12; folate levels were seemingly high. The overall prevalence of anemia was $9.6 \%$, but there were pockets of anemia in certain districts. Almost $42 \%$ of the anemia in our sample was explained by iron deficiency. There were significant differences in iron deficiency between girls and boys, $29.5 \%$ vs. $15.7 \%$, respectively ( $p=0.0001$ ). There were no cases of lead toxicity in the studied sample.

Conclusions: Wheat flour and salt fortification has had a major influence on improving the micronutrient status of Palestinian children, for some but not all micronutrients. The recommended key blood and biochemical parameters to be incorporated in the surveillance system are iron, zinc, and vitamin B12.
\end{abstract}

Keywords: Palestine, Children, Micronutrient, Anemia, Fortification

\section{Background}

Micronutrient deficiencies are a major global health problem. Vitamin A, iron, and zinc deficiencies have the largest remaining disease burden among the micronutrients considered [1]. Most people with micronutrient deficiencies live in low income countries and are typically deficient in more than one micronutrient [2]. While adequate nutritional status is an obvious building block of

\footnotetext{
* Correspondence: salwamassad@gmail.com

'Juzoor for Health and Social Development, Ramallah 970, Palestine Full list of author information is available at the end of the article
}

human capital, it is paramount in the early stages of life. If early life nutritional demands are not met, the farreaching and long lasting consequences on both individuals and society include: poorer adult health, lower educational attainment, a diminished work capacity, and ultimately a lower lifetime earning potential [3].

Micronutrient deficiencies are among the key nutrition challenges facing the Eastern Mediterranean Region (EMR) and the Arab world. Several micronutrient deficiencies including low levels of iron, iodine, zinc, calcium, folate, and vitamins A and D are still being reported from

(C) The Author(s). 2020 Open Access This article is licensed under a Creative Commons Attribution 4.0 International License, which permits use, sharing, adaptation, distribution and reproduction in any medium or format, as long as you give appropriate credit to the original author(s) and the source, provide a link to the Creative Commons licence, and indicate if changes were made. The images or other third party material in this article are included in the article's Creative Commons licence, unless indicated otherwise in a credit line to the material. If material is not included in the article's Creative Commons licence and your intended use is not permitted by statutory regulation or exceeds the permitted use, you will need to obtain permission directly from the copyright holder. To view a copy of this licence, visit http://creativecommons.org/licenses/by/4.0/. The Creative Commons Public Domain Dedication waiver (http://creativecommons.org/publicdomain/zero/1.0/) applies to the data made available in this article, unless otherwise stated in a credit line to the data. 
many countries of EMR, particularly among children and women of childbearing age [4]. When compared to other developing countries, anemia in the Arab world appears to be a moderate public health problem, with prevalence ranging from 20 to $40 \%$ [5]. The most common type of anemia in all Arab countries is iron deficiency anemia; about $50 \%$ of anemia cases are due to iron deficiency, although this proportion varies between different population groups and regions [5].

As of 2017, 4.78 million Palestinians lived in the State of Palestine. Of those, 2.99 million resided in the West Bank and 1.99 million resided in the Gaza Strip. Of the total Palestinian population, $41 \%$ are refugees. $26 \%$ of the Refugee population lives in the West Bank while the remaining 64\% reside in the Gaza Strip [6]. As of 2013, $45 \%$ of the total Palestinian population was composed of children, with $43 \%$ of them living in the West Bank and $48 \%$ in the Gaza Strip [7]. Restrictions on the movement of Palestinian goods and people were imposed in September 2000 following the second intifada (uprising), affecting movement both across borders and within the Palestinian Territory. These restrictions have been accompanied by an increase in the rate of stunting in children under the age of 5 , where the prevalence in the West Bank has risen from 7\% in 1996 to $11 \%$ in 2010 [8]. Moreover, 33\% of Palestinian households were food insecure in 2010 [9].

In Palestine, as a strategy to combat micronutrient deficiencies, salt iodization was initiated in 1996 [10], and wheat flour was fortified with eight vitamins (vitamins A, D, B-1, B-2, niacin, B-6, folic acid, and B-12), and 2 trace minerals (iron and zinc) in 2006. The flour fortification formula is shown in Table 1. Wheat flour is widely consumed in Palestine in the form of bread and is affordable to groups vulnerable to micronutrient deficiencies [10].

Despite the plethora of studies from other regions of the world, there is a paucity of data on micronutrient deficiency in Palestine overall. Previous studies on micronutrient deficiencies in Palestine were conducted mostly in small groups in the West Bank and Gaza Strip among preschool children in marginalized areas, adolescents in north Gaza and two districts in the West Bank, and pregnant women attending the United Nations Relief and Works Agency for Palestine Refugees in the Near East (UNRWA) clinics, where almost all surveyed only anemia prevalence [11-14].

In the present study, a cross-sectional survey was carried out to assess the nutritional status of a sample of randomly selected children and adolescents attending UNRWA and government schools in the West Bank. The study objectives were to identify key blood and biochemical parameters to incorporate in a surveillance
Table 1 Palestinian Flour Fortification Formula (Palestinian National Authority, Ministry of Health, Primary Health Care \& Public Health Directorate, 2015)

\begin{tabular}{|c|c|c|}
\hline & $\begin{array}{l}\text { Average addition } \\
\text { level }\end{array}$ & $\begin{array}{l}\text { Minimum-maximum } \\
\text { level }^{\mathrm{a}}\end{array}$ \\
\hline Iron (ferrous sulfate) (mg/kg) & 34.4 & $25.0-60.0$ \\
\hline Zinc (zinc oxide) (mg/kg) & 20.6 & $15.0-40.0$ \\
\hline Folic acid (mg/kg) & 1.5 & $1.0-2.5$ \\
\hline Vitamin B12 ( $\mu \mathrm{g} / \mathrm{kg})$ & 4.0 & $\min .2 .5$ \\
\hline $\begin{array}{l}\text { Thiamine (mononitrate) (mg/ } \\
\text { kg) }\end{array}$ & 2.9 & $\min .2 .0$ \\
\hline Riboflavin (mg/kg) & 3.6 & $\min .2 .5$ \\
\hline $\begin{array}{l}\text { Vitamin B6 (pyridoxine) (mg/ } \\
\text { kg) }\end{array}$ & 3.6 & $\min .2 .5$ \\
\hline Niacin (niacinamide) (mg/kg) & 35.0 & $\min .25 .0$ \\
\hline $\begin{array}{l}\text { Vitamin A (palmitate, CWS-250) } \\
(\mathrm{mg} / \mathrm{kg})^{\mathrm{b}}\end{array}$ & 1.5 & $1.00-2.5$ \\
\hline $\begin{array}{l}\text { Vitamin } D_{3}(100 \text { CWS/A) (mg/ } \\
\text { kg) }\end{array}$ & 0.023 & $0.015-0.050$ \\
\hline
\end{tabular}

${ }^{\mathrm{a}}$ Minimum and safe maximum levels of fortification

${ }^{\mathrm{b}} \mathrm{CWS}$ cold water soluble, CWS/A cold water soluble, coated w. gum Arabic

system; and offer evidence-based information to direct policies and nutritional interventions.

\section{Methods}

\section{Sampling design}

A sample of West Bank students were randomly selected from UNRWA and government schools for a 2009 cross-sectional school-based survey. The UNRWA and the government provide the bulk of free education in Palestine, serving over $85 \%$ of students $[15,16]$. In order to sample the schools, the West Bank was divided into three geographical areas (north, middle, and south) each accounting for roughly one- third of the total school children population. Schools with at least 50 students (both girls and boys) in three selected grades were sampled for this study. UNRWA and government school students were stratified by region, sex, and school year (grade). The sample size required to report prevalence data (i.e., the percentage of first graders with stunting) was calculated using a one-sample proportion tests, with $80 \%$ power for a pre-set type 1 error of $5 \%$ for the main variables to be investigated. The proportion test returned a required sample size of 500 for each age group included in the study. The three age groups were as follows: first grade (mean age 6.71 years [SD 0.45]), sixth grade (mean age 11.82 years [SD 0.57]), and ninth grade (mean age 14.83 years [SD 0.61]).

The initial plan was to select six government schools and six UNRWA schools to cover the north, central, and southern regions of the West Bank, then to randomly select 42 students from each grade and class. This would have yielded $504\left(42^{*} 12\right)$ students from each grade, with 
252 boys and 252 girls. The plan had to be amended to accommodate the realities of UNRWA and government schools in the region.

First, students were randomly recruited from 16 rather than 4 UNRWA schools. This resulted from the selection of two camps from each region and the fact that in some UNRWA schools, the elementary school and preparatory school are separate (requiring the selection of four schools rather than two). In light of these considerations, six government and 16 UNRWA schools were selected from 1555 UNRWA and government schools. Second, it was found that some of the government schools incorrectly reported the number of students in each class; in some cases, the school did not have enough students to allow the random selection of 42 students from each grade. Consequently, only 681 students were selected from government schools (rather than 756 as initially planned). From UNRWA schools 819 students were then selected to make up the required total of 1500 . One student per household was selected to avoid clustering.

For each study index, two measurements of the standing height and weight (lightly dressed, shoes removed) were taken by trained field workers on visits to the participating schools. A third measurement was taken if the difference between the two measurements was greater than $10 \%$. Mothers were invited to attend their children's schools on the day of the visit and were asked to provide information regarding socio-demographic characteristics. In the case of first grade students, mothers were asked to complete the student survey on behalf of their children. Sixth and ninth grade students were asked to complete a survey regarding their physical activity and the number of hours spent watching TV, among other variables.

\section{Laboratory measurements}

Blood ( $5 \mathrm{~mL}$ ) was obtained by venipuncture. To check validity of test results, two types of quality assurance program were used, internal and external quality control. Internal quality control was carried out for all lab tests, where three different levels of control were used with every batch of samples analyzed. Assays were externally validated for vitamin B12, ferritin, and folic acid levels using control quality assurance samples provided by the Centers for Disease Control and Prevention (CDC). The CDC - External Quality Assurance (EQA) program is a standardization program designed to provide laboratories with an independent assessment of their analytical performance. The blind samples were sent by the CDCEQA program to Ramallah. A complete blood cell count was performed with a Fully Automated Hematology Analyzer by Cell Dyne 1700an. Thyroid hormones, vitamin B12, folate, and ferritin were determined using a
Chemiluminesence assay using ADVIA Centaur USA, by Siemens. C-reactive protein (CRP) was determined by the ELISA technique using commercially available kits (Quantikine Human, R\&D Systems, Minneapolis, MN). Zinc content was measured using atomic absorption spectrophotometer blood. Lead was determined in a randomly selected $50 \%$ of the samples using Leadcare Analyzer, ESA Biosciences. A capillary tube was used to draw a small amount of blood (approximately two drops) and deposited in the Leadcare system. Leadcare controls were done for each test kit.

In addition to the internal quality control procedures, we took the following measures in examining $\mathrm{Fe}, \mathrm{Zn}$, and lead:

- The venipuncture site was cleaned with alcohol.

- A closed-tube vacuum system was used to avoid mineral contamination.

- Special metal-free blood containers were used to minimize the potential for sample contamination by any outside sources of minerals.

- Blood was drawn in a BD Royal Blue with K2 EDTA Vacutainer tube (Supply T183).

- Lead blood specimens were drawn in a BD Tan with K2 EDTA, lead only (EDTA) Vacutainer tube (Supply T615).

- All tubes were kept in dark cool boxes $\left(0-4{ }^{\circ} \mathrm{C}\right)$ and transported to the central lab.

For quality control, double data entry was used for all lab tests, in addition to survey data. Students with elevated CRP were excluded from ferritin and zinc analyses.

\section{Variables}

Low Mean Corpuscular Volume (MCV) was defined as $\mathrm{MCV}<75 \mathrm{fL}$.

Iron deficiency was defined as serum ferritin below $15 \mathrm{ng} / \mathrm{ml}$ based on WHO guidelines [17].

Anemia: Based on WHO guidelines, anemia was defined as hemoglobin $(\mathrm{Hb})$ below $11.5 \mathrm{~g} / \mathrm{dl}$ for children 5-11 years; below $12 \mathrm{~g} / \mathrm{dl}$ for children $12-14$ years; and girls $\geq 15$, and below $13 \mathrm{~g} / \mathrm{dl}$ for boys $\geq 15$ years [17].

Iron deficiency anemia: was defined as having both anemia and iron deficiency.

Serum folate: levels of $7-20 \mu \mathrm{g} / \mathrm{L}$ were defined as nor$\mathrm{mal}$; levels of $<3.1 \mu \mathrm{g} / \mathrm{L}$ were defined as very low, levels of $<7.0 \mu \mathrm{g} / \mathrm{L}$ ) were defined as low, and levels of $>20 \mu \mathrm{g} /$ $\mathrm{L}$ were defined as high [18].

Iodine deficiency: iodine deficiency was defined by a low thyroxine which was determined according to the manufacturer's instructions as tri-iodothyroxine (FT3) < $2.3 \mathrm{pg} / \mathrm{ml}$, thyroxine hormone (FT4) $<0.89 \mathrm{~g} / \mathrm{dl}$, and thyroid-stimulation hormone $(\mathrm{TSH})>5.5 \mathrm{uIU} / \mathrm{ml}$. 
Vitamin B12: levels were defined as B12 deficient (< $221 \mathrm{pg} / \mathrm{ml})$ and marginal $(<300 \mathrm{pg} / \mathrm{ml})$ [19].

Serum Zinc: low levels were defined as $<65 \mu \mathrm{g} / \mathrm{dl}$ [20]. $C$-reactive protein (CRP): Elevated levels were defined $>11 \mathrm{mg} / \mathrm{l}[21]$.

Lead: High levels were defined as $>10 \mu \mathrm{g} / \mathrm{dl}$ [22].

\section{Statistical analysis}

SAS (SAS Institute, Cary, NC) software was used to analyze the dataset of 1484 subjects. Means and percentages were used to describe the characteristics of the study sample. Chi-square test was performed to examine differences in micronutrient deficiency by gender, school affiliation, and grade level. Tests of significance were two-sided with $p$-value $\leq 0.05$. The effect of fortification on the prevalence of micronutrient deficiencies was evaluated based on previous reports and an earlier baseline study in Hebron/West Bank in 2005 [23].

\section{Results}

\section{Study sample}

Data were obtained from 1484 (99\%) of 1500 students; males accounted for $49.7 \%$ of the study population. The response rate for blood samples from the students was $98 \%$. Baseline characteristics of the study sample are published in an earlier study [24]. Forty-six percent of the students were from government schools.

\section{Micronutrient status}

The micronutrient status of the study sample is presented in Fig. 1. The students with elevated CRP $(2.6 \%$ of total students) were excluded from the ferritin and zinc analyses. There were gender and grade level differences in most micronutrient levels (Table 2).Anemia, iron deficiency, and iron deficiency anemia.

The overall prevalence of anemia was $9.6 \%$, with significant gender differences: $12.1 \%$ girls and $7.1 \%$ boys $(p=0.001)$. There was also a significant difference by school affiliation; the prevalence of anemia was higher in UNRWA schools compared to government schools, at $13.3 \%$ vs. $5.3 \%$, respectively $(p=0.0001)$. The prevalence of anemia was highest in Jericho and lowest in Ramallah (Fig. 2). However, there was no statistically significant differences by grade level in overall anemia (first grade: 8.9\% (95\% CI 6.4-11.4\%), sixth grade, 8.0\% (5.6-10.4\%), and ninth grade, $12.1 \%$ (9.2-15.0\%). Forty-two percent of children with anemia had iron deficiency.

There were significant differences in iron deficiency between girls and boys, $29.5 \%$ vs. $15.7 \%$, respectively $(p=0.0001)$. There were also significant differences by grade level: 19.7\% among first grade students, $18.7 \%$ among sixth graders, and $29.9 \%$ among ninth graders $(p=0.0001)$. As is the case with anemia, there were school statistically significant differences in iron deficiency, $26.3 \%$ in UNRWA schools and $18.5 \%$ in government schools $(\mathrm{p}=0.0001)$.

Overall prevalence of iron deficiency anemia (IDA) was $4 \%$ : $6.2 \%$ among females and $1.8 \%$ among males. More students (5.8\%) from UNRWA schools had iron deficiency anemia compared to $1.9 \%$ of those from government schools $(p=0.0001)$. As shown in Fig. 2 , there was marked variability in iron deficiency and iron deficiency anemia by gender and district. Across all districts, except Ramallah, iron deficiency explained more than $50 \%$ of anemia among females.

\section{MCV levels}

In general, $\mathrm{MCV}$ was low among a substantial number of schoolchildren; $18.8 \%$ had low MCV.

\section{Folate levels}

Based on study findings, low folate was not a concern. On the other hand, $25.3 \%$ had elevated serum folate levels $(>20 \mu \mathrm{g} / \mathrm{L})$.

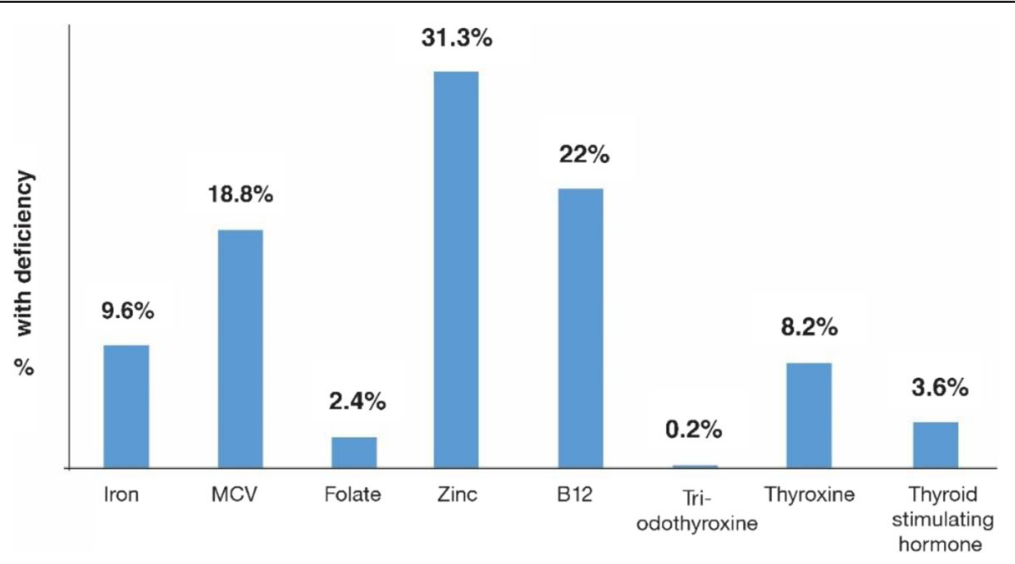

Fig. 1 Prevalence of low micronutrient levels in the study population 
Table 2 Micronutrient status of the study sample by gender and grade level, $(N=1484), 2009$

\begin{tabular}{|c|c|c|c|c|c|c|c|}
\hline \multirow{3}{*}{ Mean age (SD) in years } & \multicolumn{7}{|c|}{$\%$ with Deficiency } \\
\hline & \multicolumn{2}{|c|}{ First Grade } & \multicolumn{2}{|c|}{ Sixth Grade } & \multicolumn{2}{|c|}{ Ninth Grade } & \multirow[t]{2}{*}{ Total } \\
\hline & \multicolumn{2}{|c|}{$6.7(0.5)$} & \multicolumn{2}{|c|}{$11.8(0.6)$} & \multicolumn{2}{|c|}{$14.8(0.6)$} & \\
\hline & Male & Female & Male & Female & Male & Female & \\
\hline $\mathrm{MCV}^{\mathrm{a}}$ & 31.3 & 16.9 & 17.1 & 16.2 & 14.9 & 13.5 & 18.8 \\
\hline \multicolumn{8}{|l|}{ Folate } \\
\hline$-(<3.1 \mu \mathrm{g} / \mathrm{L})$ & 0 & 0 & 0 & 0.4 & 0 & 0.4 & 0.1 \\
\hline$-(<7.0 \mu \mathrm{g} / \mathrm{L})$ & 0.4 & 2.4 & 1.2 & 1.6 & 3.8 & 4.9 & 2.4 \\
\hline$-(>20 \mu \mathrm{g} / \mathrm{L})$ & 29.3 & 33.3 & 22.4 & 32.7 & 18.2 & 15.5 & 25.2 \\
\hline Zinc $^{2}$ & 34.7 & 35.7 & 32.2 & 33.6 & 20.0 & 31.0 & 31.3 \\
\hline \multicolumn{8}{|l|}{ B12 } \\
\hline - Marginal $\left.\right|^{3}$ & 26.8 & 37.3 & 41.6 & 37.1 & 46.6 & 39.2 & 40.0 \\
\hline - Deficient ${ }^{4}$ & 15.9 & 13.5 & 21.2 & 27.8 & 36.0 & 19.2 & 22.0 \\
\hline \multicolumn{8}{|l|}{ Thyroid hormones } \\
\hline - Tri-iodothyroxine $e^{5}$ & 0 & 0 & 0 & 0.8 & 0.4 & 0 & 0.2 \\
\hline - Thyroxine hormone ${ }^{6}$ & 3.7 & 2.8 & 6.1 & 10.9 & 14.4 & 12.2 & 8.2 \\
\hline - Thyroid- stimulation hormone ${ }^{7}$ & 6.1 & 4.0 & 2.9 & 5.2 & 1.3 & 2.5 & 3.6 \\
\hline
\end{tabular}

${ }^{\mathrm{a}} \mathrm{MCV}<75 \mathrm{fL},{ }^{2} \mathrm{Zinc}<65 \mu \mathrm{g} / \mathrm{dL},{ }^{3} \mathrm{~B} 12<300 \mathrm{pg} / \mathrm{mL},{ }^{4} \mathrm{~B} 12<221 \mathrm{pg} / \mathrm{ml},{ }^{5} \mathrm{FT} 3<2.3 \mathrm{pg} / \mathrm{mL},{ }^{6} \mathrm{FT} 4<0.89 \mathrm{~g} / \mathrm{dL} .{ }^{7} \mathrm{TSH}>5.5 \mathrm{ulU} / \mathrm{mL}$

\section{Serum zinc levels}

About $31 \%$ of the study sample had zinc deficiency in a geographic distribution that approximates that of iron deficiency, with significant gender differences, $33.5 \%$ among females vs. $29.1 \%$ among males $(p=$ $0.04)$. There was also significant variation in zinc deficiency by grade level: $35.2 \%$ among first graders, $32.9 \%$ among sixth graders, and $25.6 \%$ among ninth graders $(p=0.003)$.

\section{Vitamin B12 levels}

Vitamin B12 levels showed statistically significant gender and grade differences, where deficiency was more common among ninth grade males $(36.0 \%$ vs $19.2 \%$ among ninth grade females, $p=0.000)$.

Iodine status.

Based on study findings, there was essentially no iodine deficiency; $0.2 \%$ had deficiency in tri-iodo thyroxine, and $3.6 \%$ had deficiency in thyroid stimulating hormone.

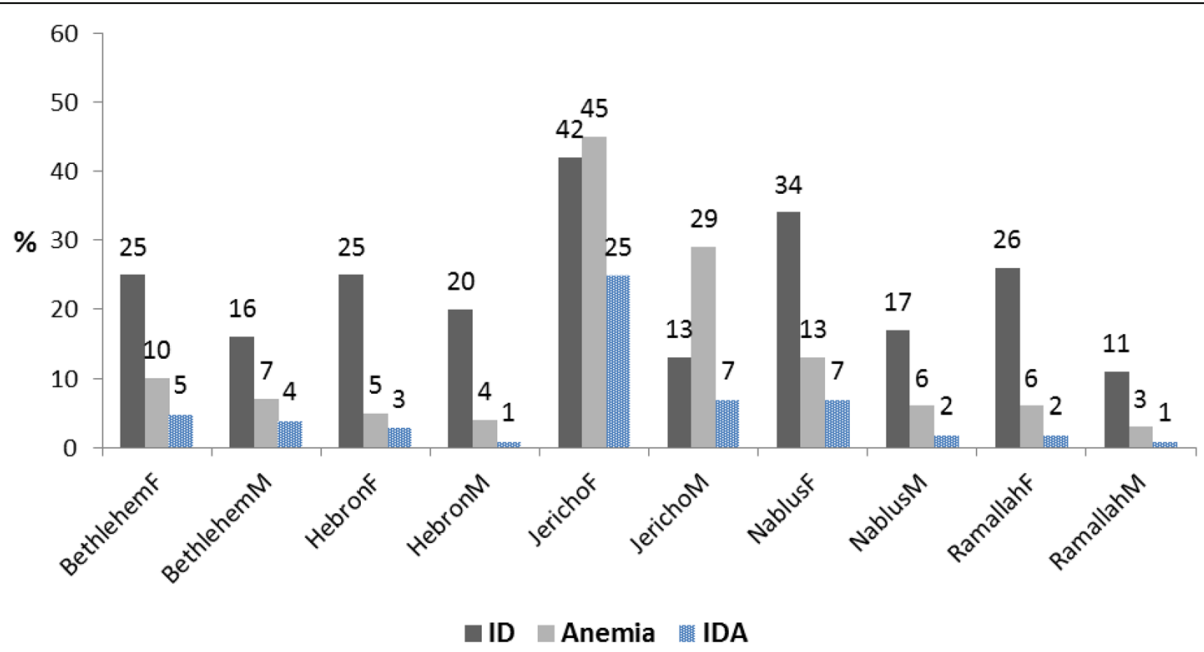

Fig. 2 Prevalence of Anemia, Iron deficiency, and Iron Deficiency Anemia by District and Gender, *Note: F: Female, M: Male, ID = iron deficiency, IDA = iron deficiency anemia 


\section{Blood Lead}

There were no cases of lead toxicity (blood lead $>10$ microgram/dl) in the study sample.

\section{Discussion}

Based on the levels of thyroid hormones reported in the study, iodine deficiency is seemingly no longer a nutritional problem in the West Bank. Based on the Palestinian Family Health survey of 2010, 77\% of households in Palestine consumed iodized salt: $68 \%$ in the West Bank and $91 \%$ in the Gaza Strip [25]. However, despite flour fortification, main nutritional micronutrient risks for schoolchildren in the West Bank were low serum levels of iron, zinc, and vitamin B-12, and there were pockets of anemia in certain districts.

It was challenging to examine the impact of flour fortification on micronutrient status of children due to following reasons. First, there is no baseline national data on anemia and micronutrient status among children before fortification to measure impact of flour fortification. The only baseline data available on micronutrient deficiency before fortification emanates from a local study of micronutrient deficiency among 366 pairs, children (37 years) and his/her non-pregnant mothers (18-50 years old) whom are randomly selected from Gaza city in Gaza Strip and Hebron in the West Bank in 2005 [23]. In Hebron, $15 \%$ of children 3-7 years old had anemia [23]. In the present study, the prevalence of anemia among children in first grade in Hebron (mean age 6.71 years [SD 0.45]) was $4.7 \%$. This may suggest that wheat fortification improved, but did not eliminate iron deficiency. Second, not all flour is fortified. According to the Palestinian Ministry of Health, in 2013, only $41 \%$ of wheat flour was actually fortified with iron in the West Bank [10]. This low percentage stems from the different sources of flour in the market, where flour from Israel and donations are not fortified.

Almost 42\% (ranged between 25 and 73\% based on grade and gender) of the anemia in our sample was explained by iron deficiency as measured by serum ferritin, in line with findings from research in Arab countries [5]. Iron deficiency among adolescent children can be explained by growth spurts and sexual maturation. Adolescent girls in particular are vulnerable to micronutrient deficiency because they need protein, iron, and other micronutrients to support the adolescent growth spurt, including increased demand for iron during menstruation.. In addition, older children may consume more outside of their home which may result in increased intake of foods with low nutritional value like salty and sweet snacks [26].

In contrast to the high prevalence of low serum ferritin, $25 \%$ of the children showed high levels of serum folate, which suggests an association with an intake of fortified wheat flour. Interestingly, the children from Bethlehem did not show as high occurrence of elevated folate levels as children from other areas. This observation may reflect higher intakes of non-fortified flour from Israel, the main source of flour in Bethlehem.

Despite fortification, low levels of B12 persist. Bioavailability of vitamin B12 is dependent on the complex production and release of proteins from the mouth and stomach, haptocorrins and intrinsic factor. Among the factors that contribute to low levels of B12 include malabsorption caused by atrophic gastritis or Helicobacter pylori infection, pancreatic or intestinal pathology, and gastric acid-reducing medications $[27,28]$. Currently, we lack adequate data to explain the low levels of B12 in the present study. Shortcomings in the fortification process may have played a role.

Our study has some limitations. First, the study was conducted among children attending public schools only; government and UNRWA schools and excluded those from private schools.

However, it included most children, as about $86 \%$ of schoolchildren in the West Bank go to public schools. Second, the study examined only school children, may not apply to other population groups. However, Palestine has a young population in which $45 \%$ of Palestinian are children. Third, we used data from 10 years ago for this paper. However, our survey describes the only micronutrient data available on a random sample of children 6-12 years. Adding to that, micronutrient deficiency is still a nutrition concern among school children along with challenges of low fortification levels in fortified flour in the West Bank. Despite these limitations, the present study is unique in several aspects. In the first instance, the subjects who took part in the study were sampled from districts in the northern, central and southern parts of the country. Furthermore, the study examined micronutrient status of different age groupsas opposed to only adolescents-that were randomly selected instead of resorting to recruitment of a convenient sample. In addition to this, several indicators of nutritional status were utilized in order to broaden and deepen attributes of the participants.

\section{Conclusions}

Our results indicate that the main nutritional micronutrient risks for schoolchildren in the West Bank continue to be low serum levels of iron, zinc, and vitamin B-12; folate levels were seemingly high; and for the whole population iodine intake appears adequate. Iron deficiency remains a public health concern among the school children, mainly 6th and 9th grade female students. With the exception of Jericho, anemia is mild in school-age children of the West Bank; although the prevalence increases in male after the 6th grade. The 
recommended key blood and biochemical parameters to be incorporated in the surveillance system are iron, zinc, and B12.

Several interventions are possible to combat anemia, iron, zinc and vitamin B12 deficiencies. First, anemia can be combatted by revising fortification levels through an increase in iron, zinc, and vitamin B12, for example. Consideration needs to be given to enforce laws for flour fortification and better control on smuggled unfortified flourfrom Israel and on donated flour based on Palestinian specification. Second, resources can be funneled into agricultural practices to enhance food availability and ensure access to particular foods [3]. Third, complementary measures can be undertaken, including dietary diversification and supplementation. Fourth, ministries need to collaborate with the local food industry to fortify food products, to offer healthy food products. Additionally, there is a need for nutritional intervention in adolescent girls before the onset of childbearing.

\section{Abbreviations}

EMR: Eastern Mediterranean Region; UNRWA: the UN Relief and Works Agency for Palestine Refugees in the Near East

\section{Acknowledgments}

Special thanks to Maysoun Obeidi for all her help in blood tests.

\section{Authors' contributions}

Conceptualization: SM, MG-M, OD, WK, PB, UK and RD; Data curation: SM, MA; Formal analysis: SM, OD and SH; Funding acquisition: UK and RD; Investigation: OD, WK, UK and RD; Methodology: SM, MG-M, OD, SH, WK, PB, UK and RD; Project administration: SM and UK; Resources: UK; Supervision: SM and UK; Validation: SM, MG-M, MA and RD; Writing - original draft: SM; Writing - review \& editing: MG-M, OD, SH, WK, PB, UK and RD. All authors have read and approved the manuscript.

\section{Funding}

This study was supported by funds from UNRWA, UNICEF, Juzoor for Health and Social Development, and the Institute of Human Nutrition, Columbia University. Dr. Abdalla received support through 18AMFDP34380732 from the American Heart Association and from K23 HL141682-01A1 from the National Heart, Lung, and Blood Institute. UNRWA and UNICEF had role in data collection; Juzoor for Health and Social Development and the Institute of $\mathrm{Hu}-$ man Nutrition had role in study design, data collection, analysis, interpretation of data, and writing the manuscript, American Heart Association, National Heart, Lung, and Blood Institute had role in data curation, and validation.

\section{Availability of data and materials}

The dataset is available upon reasonable request.

\section{Ethics approval and consent to participate}

The study protocol was approved in December 2008 by Columbia University's Institutional Review Board (New York, USA) and Al-Quds University (Jerusalem, Palestine). Written informed consent and assent were obtained from sixth and ninth grade students as well as their parents.

\section{Consent for publication}

Not applicable.

\section{Competing interests}

The authors declare that they have no competing interests.

\section{Author details}

'Juzoor for Health and Social Development, Ramallah 970, Palestine. ${ }^{2}$ Department of Women's and Children's Health, Pediatrics, University Hospital, SE-751 85 Uppsala, Sweden. ${ }^{3}$ USAID Bureau of Global Health, Washington, DC, USA. ${ }^{4}$ Division of Cardiology, Department of Medicine, Columbia University Irving Medical Center, New York, NY 10032, USA. 5 Institute of Human Nutrition, Columbia University, New York, NY 10032, USA. IIrving Institute for Clinical and Translational Research, Columbia University Irving Medical Center, New York, NY 10032, USA. ${ }^{7}$ Mailman School of Public Health, Columbia University Irving Medical Center, New York, NY 10032, USA. ${ }^{8}$ Department of Pediatrics, Vagelos College of Physicians and Surgeons, Columbia University Irving Medical Center, New York, NY 10032, USA.

Received: 29 November 2019 Accepted: 30 July 2020

Published online: 26 August 2020

\section{References}

1. Black RE, Allen LH, Bhutta ZA, Caulfield LE, De Onis M, Ezzati M, Mathers C, Rivera J. Maternal and child undernutrition: global and regional exposures and health consequences. Lancet. 2008;371(9608):243-60.

2. United Nations Children's Fund. Preventing and controlling micronutrient deficiencies in populations affected by an emergency 2006. http://www. unicef.org/nutrition/files/Joint_Statement_Micronutrients_March_2006.pdf Accessed on 28 June 2019.

3. Bailey RL, West KP Jr, Black RE. The epidemiology of global micronutrient deficiencies. Ann Nutr Metab. 2015;66:22-33.

4. World Health Organization Regional Office for the Meditarrean Region. Micronutrients. 2019. http://www.emro.who.int/health-topics/ micronutrients/index.html Accessed on 28 June 2019.

5. Musaiger AO, Hassan AS, Obeid O. The paradox of nutrition-related diseases in the Arab countries: the need for action. Int J Environ Res Public Health. 2011:8:3637-71.

6. Palestinian Central Bureau of Statistics: On the occasion of the International Population Day 11/7/2019. Ramallah, Palestine; 2019.

7. Palestinian Central Bureau of Statistics: Palestinian Children's Day 2019. Ramallah-Palestine; 2019

8. Palestinian Central Bureau of Statistics. Palestinian Children- Issues and Statistics. In: Child Statistics Series; 2011

9. Joint press release by the Palestinian Central Bureau of Statistics (PCBS), the Food and Agriculture Organization (FAO), the United Nations Relief and Works Agency for Palestine Refugees in the Near East (UNRWA) and the World Food Programme (WFP). Food Insecurity. In: Palestine Remains High; 2014.

10. Elmadfa I, Ben-Abdullah K, Meyer AL, Ramlawi A, Bahar L, Rizkallah N, Skaik A, Zakout Z, El-Aissawi F. Palestinian micronutrient survey (PMS) 2013. Ramallah-Palestine: United Nations Children's Fund office in the State of Palestine and Palestinian Ministry of Health; 2014.

11. Mikki N, Abdul-Rahim HF, Stigum H, Holmboe-Ottesen G. Anaemia prevalence and associated sociodemographic and dietary factors among Palestinian adolescents in the West Bank. EMHJ. 2011;17(3):208-217 28.

12. Sirdah MM, Yaghi A, Yaghi AR. Iron deficiency anemia among kindergarten children living in the marginalized areas of Gaza strip, Palestine. RevistaBrasileira de Hematologia e Hemoterapia. 2014;36:132-8.

13. Abudayya A, Thoresen M, Abed Y, Holmboe-Ottesen G. Overweight, stunting, and anemia are public health problems among low socioeconomic groups in school adolescents (12-15 years) in the North Gaza strip. Nutr Res. 2007;27:762-71.

14. Khader A, Madi H, Riccardo F, Sabatinelli G. Anaemia among pregnant Palestinian women in the occupied Palestinian territory. Public Health Nutr. 2009;12:2416-20.

15. Ministry of Education and Higher Education. Annual statistics report for the school year 2014-2015. Beirut: Ministry of Education and Higher Education; 2015.

16. Ministry of Education and Higher Education. Palestine education for all 2015 national review. Beirut: Ministry of Education and Higher Education; 2015.

17. World Health Organization. Haemoglobin concentrations for the diagnosis of anaemia and assessment of severity. http://www.who.int/vmnis/ indicators/haemoglobin.pdf. Accessed on June 28, 2019.

18. World Health Organization. Serum and red blood cell folate concentrations for assessing folate status in populations. http://apps.who.int/iris/bitstream/1 0665/75584/1/WHO_NMH_NHD_EPG_12.1_eng.pdf Accessed on June 28, 2019. 
19. de Benoist B. Conclusions of a WHO technical consultation on folate and vitamin B12 deficiencies. Food Nutr Bull. 2008;29:\$238-44.

20. International Zinc Nutrition Consultative Group. International Zinc Nutrition Consultative Group (IZiNCG) technical document\# 1. Assessment of the risk of zinc deficiency in populations and options for its control. Food Nutr Bull. 2004;25:S99-S203.

21. Adu-Afarwuah S, Lartey A, Brown KH, Zlotkin S, Briend A, Dewey KG. Home fortification of complementary foods with micronutrient supplements is well accepted and has positive effects on infant iron status in Ghana. Am J Clin Nutr. 2008;87:929-38.

22. Brown M. Interpreting and managing blood lead levels $<10 \mu \mathrm{g} / \mathrm{dL}$ in children and reducing childhood exposures to lead. MMWR Recomm Rep. 2007:56:1-14.

23. Lindsay A. Nutritional status in Gaza city and Hebron. USDA: ARS Western Human Nutrition Research Center. University of California, Davis; 2006.

24. Massad S, Deckelbaum RJ, Gebre-Medhin M, Holleran S, Dary O, Obeidi M, Bordelois $\mathrm{P}$, Khammash U. Double burden of undernutrition and obesity in Palestinian schoolchildren: a cross-sectional study. Food Nutr Bull. 2016;37: 144-52.

25. Palestinian Central Bureau of Statistics. Palestinian health survey 2010 final report. Ramallah: Palestinian Central Bureau of statistics; 2013.

26. Best C, Neufingerl N, van Geel L, van den Briel T, Osendarp S. The nutritional status of school-aged children: why should we care? Food NutrBul. 2010;31: 400-17.

27. Muhsen K, Barak M, Henig C, Alpert G, Ornoy A, Cohen D. Is the association between helicobacter pylori infection and anemia age dependent? Helicobacter. 2010;15:467-72.

28. Etcheverry P, Grusak M, Fleige L. Application of in vitro bio-accessibility and bioavailability methods for calcium, carotenoids, folate, iron, magnesium, polyphenols, zinc, and vitamins B6, B12, D, and E. Front Physiol. 2012;3:317.

\section{Publisher's Note}

Springer Nature remains neutral with regard to jurisdictional claims in published maps and institutional affiliations.

Ready to submit your research? Choose BMC and benefit from:

- fast, convenient online submission

- thorough peer review by experienced researchers in your field

- rapid publication on acceptance

- support for research data, including large and complex data types

- gold Open Access which fosters wider collaboration and increased citations

- maximum visibility for your research: over $100 \mathrm{M}$ website views per year

At $\mathrm{BMC}$, research is always in progress.

Learn more biomedcentral.com/submissions 